Faculty of Veterinary Medicine,

Al-Baath University, Syria.

\title{
EFFECT OF ADD ENZYMES ON PRODUCTION EFFICIENCY ON CHICKEN
}

(With 14 Tables)

\author{
تأثير إضافة الأنظيمات على الكفاءة الإنتاجية في الفروج \\ (Received at 19/11/2011)
}

\section{نايف الجدوع ، أحمد مفيل صبح ، حسن طرشة}

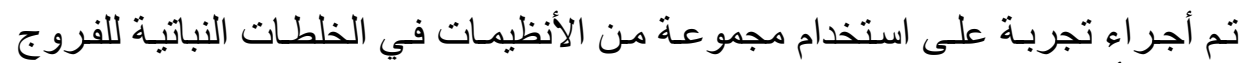

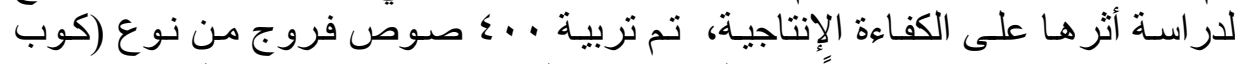

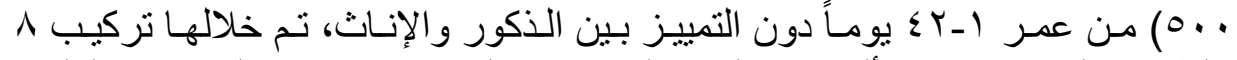

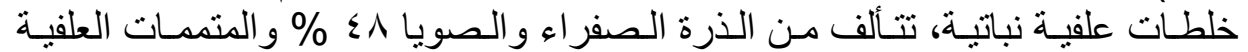

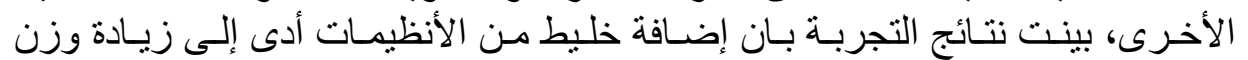

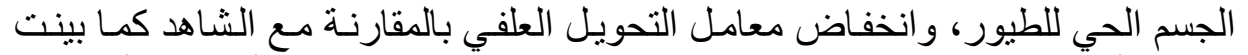

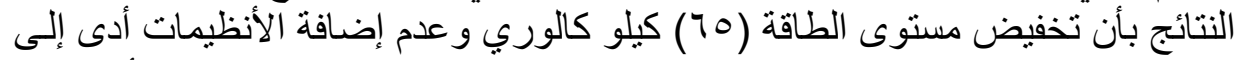

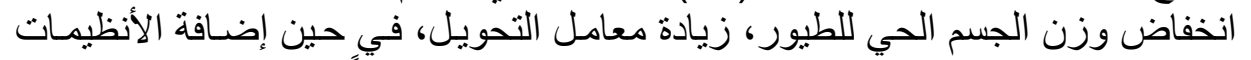

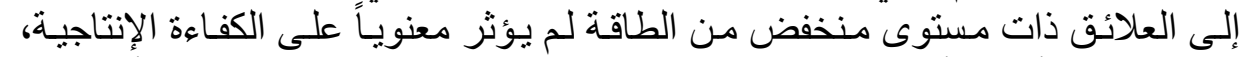

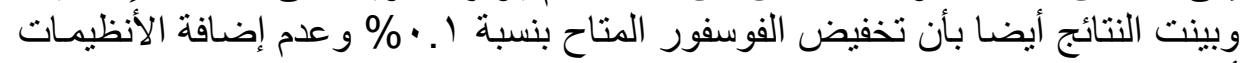

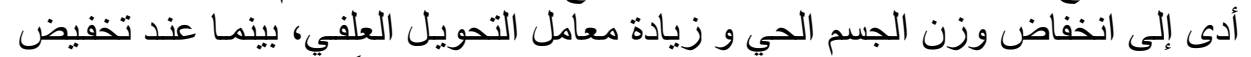

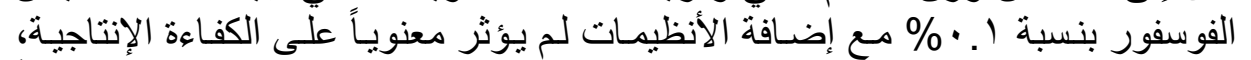

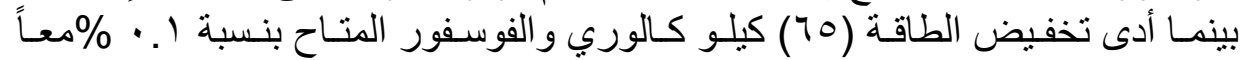

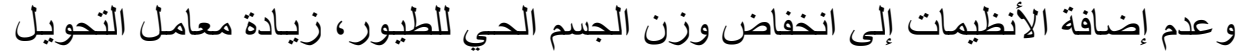

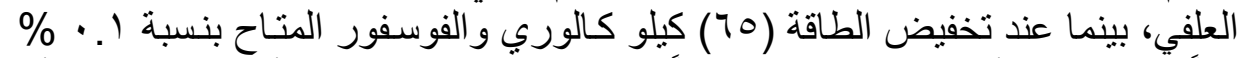

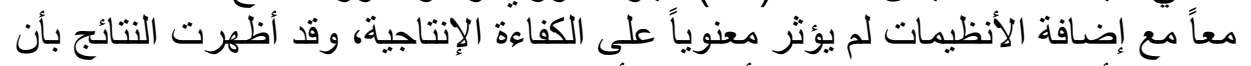

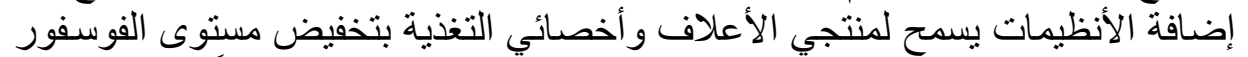

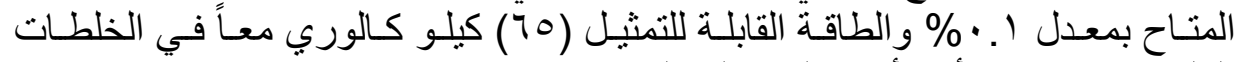
العلفية دون حدوث أي تأثثير سلبي على الكفاءة الإنتاجية. 


\section{SUMMARY}

Birds of (cobb 200) were fed on 8 plant mixes "maize" soya $48 \%$ and other feed supplements from 1-42 days. The results showed that adding enzymes mix increased the body weight of the birds accompanied by efficient feed conversion compared to the control. The results proved that adding enzynes to low energy (65) kilo calories diet did not affect either the feed conversion of the body weight on the contrary to the results obtained where the birds fed on low energy diet without any enzyme supplementaion. The same trend was followed for the phosphorus when the level decreased to $(0.1 \%)$. Also the effect of the enzymes mix was very clear with the diets with low levels in both energy and phosphorus.

Key words: Birds of cobb, maize soya, enzyme supplementation.

\section{INTRODUCTION}

\section{المــدمـة}

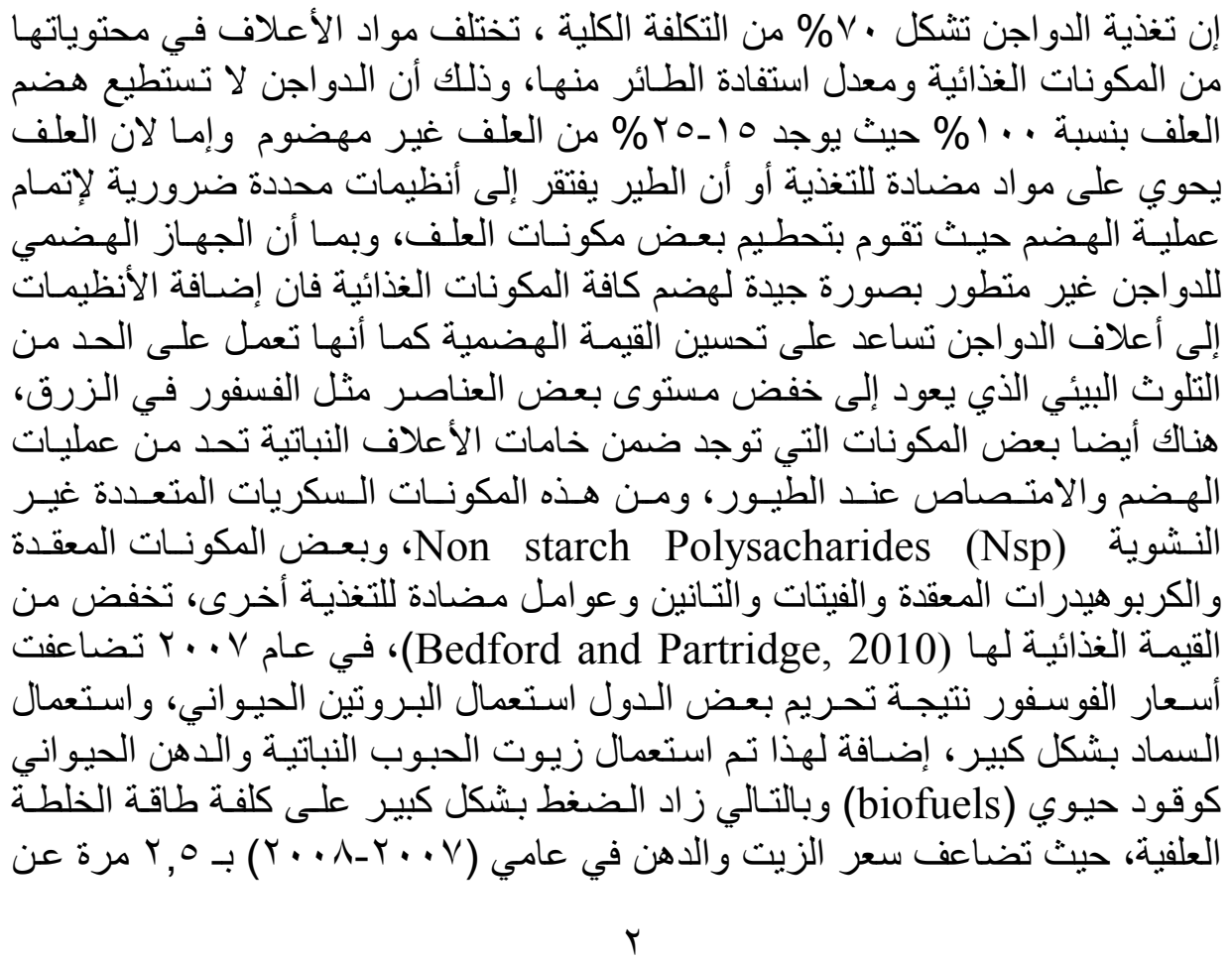




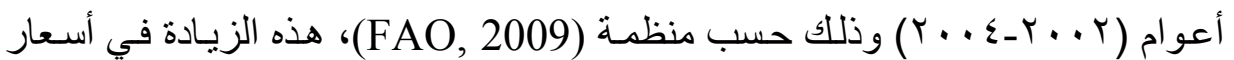

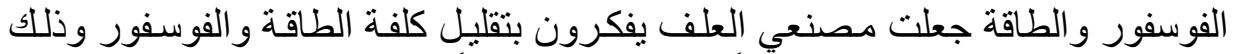

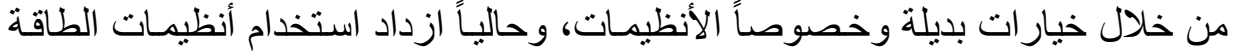

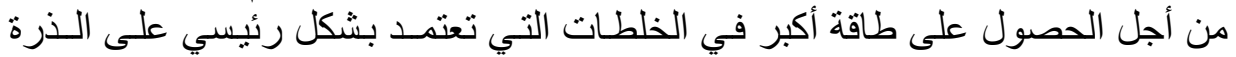
و الصويـا عن السابـق (Cowieson and Ravindran, 2008ab ; Janet, 2008). أهـدف البـحث

1 - تحسين الكفاءة الإنتاجية من خلال تحسين الاستفادة من الطاقة القابلة للتمثيل

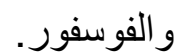
r- الاقتصاد في استخدام الفوسفور المضاف إلى الخلطة العلفية وذلك بتحسين الاستفادة

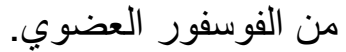
r- حماية البيئة بتقليل الفوسفور المطرو الفئوح مع الزرق.

الدراسة المرجعية: Review of Literature

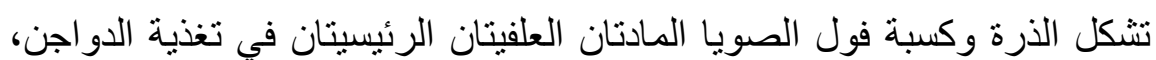

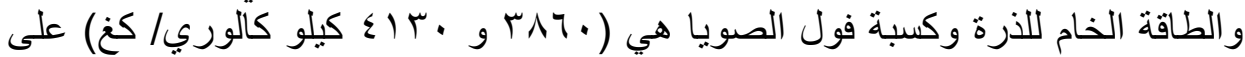

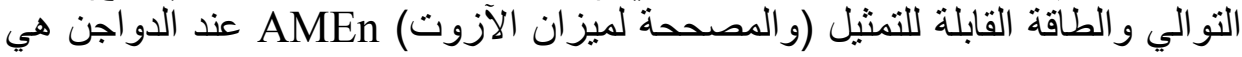

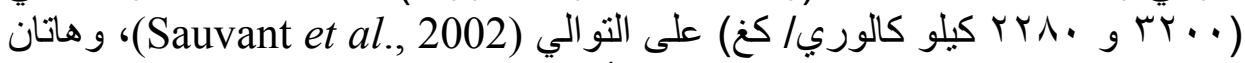

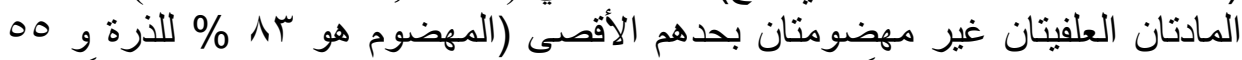

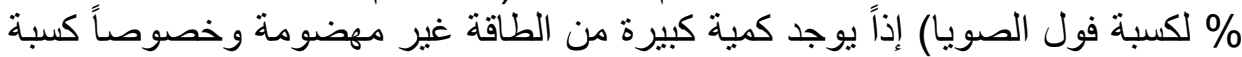

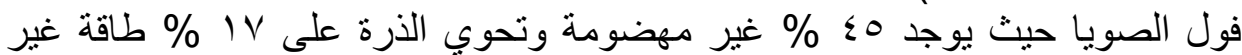

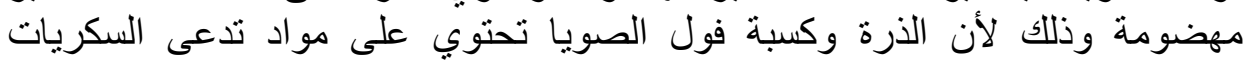

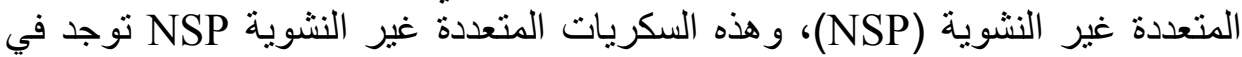

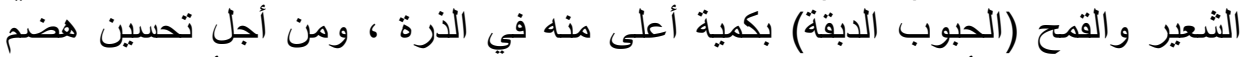

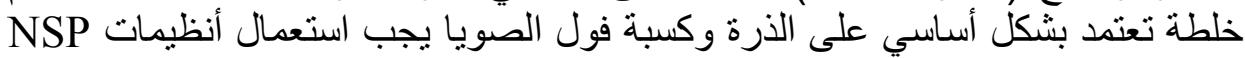
من أجل تحليل السكريات المتعددة غير النشوية (NSP) و السكريات فئل المتعددة .(et al., 2001)

وقد فسّر Cowieson (2005) ذلك التحسن بأن الأنظيمات تقوم بتحطيم جدر

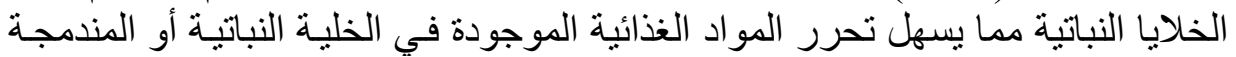

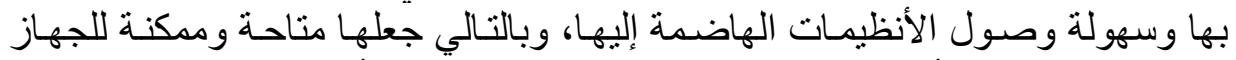
الهضمي للطائر من أجل الاستفادة منها، وقد يستدل بهذا على أنى أن إضافة

الأنظيمات للخلطات المكونة بشكل أساسي من الذرة وكسبة فول الصويا يحسن القيمة الغذائية لهذه الخلطات.

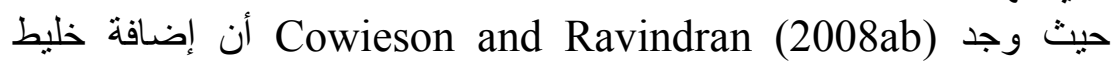

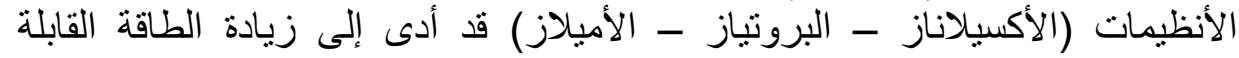

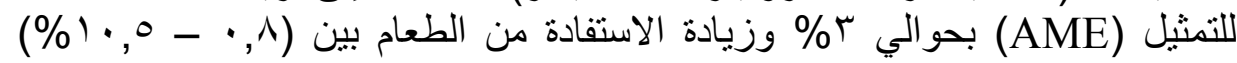


وزيادة الاستفادة من الآزوت (v, (1\%) مع زيادة الوزن الحي بمقار

. (\% \% 9

وجد الباحثان Dalibard and Geraert (2004) أن تخفيض الطاقة قد أدى

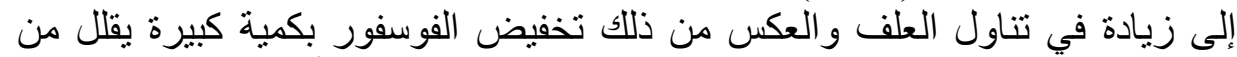

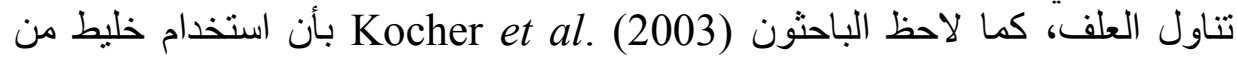
الأنظيمات يحوي على (الأكسيلاز، الأميلاز، البروتياز ، الفيتاز) أي الأنظيمات المحللة الإنة

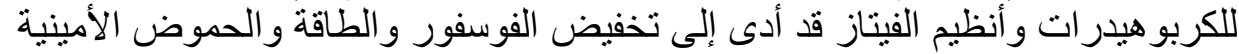

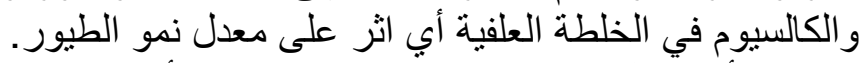

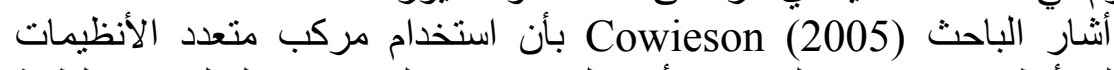

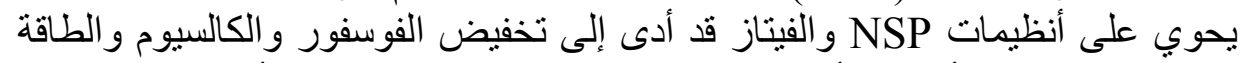
وبعض الحموض الأمينية الأساسية في الخلطة العلفية المعتمدة بشكل أساسي على الذالى الذرة وكسبة فول الصويا بدون خسارة في الأداء (النمو).

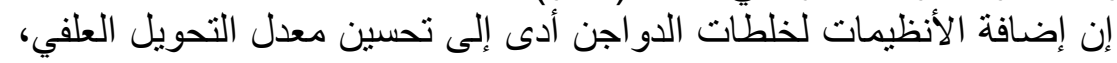

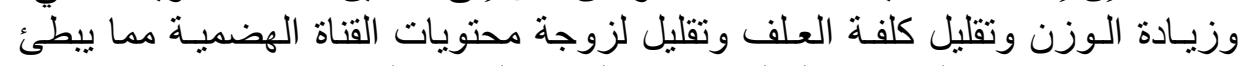

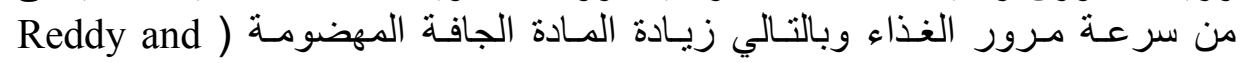
(Scheideler et al., 2005 Zanella et al., 1999; Quadratullah, 1997 استخدم أخصائيو التغذية أنظيمات تضاف إلى العلف وذلك من أجل تخفيض

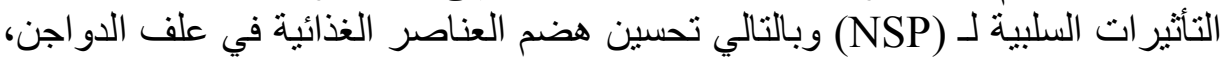

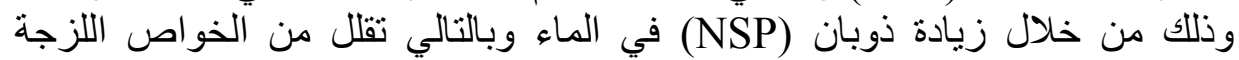

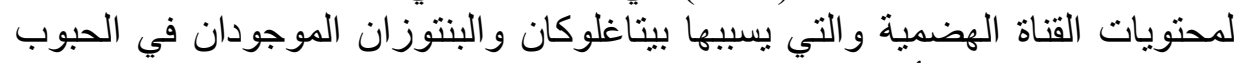

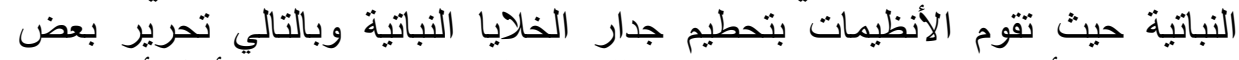

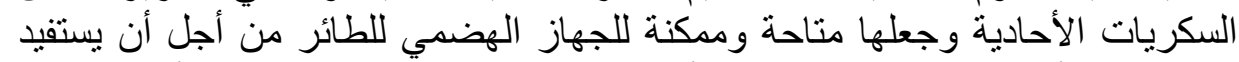

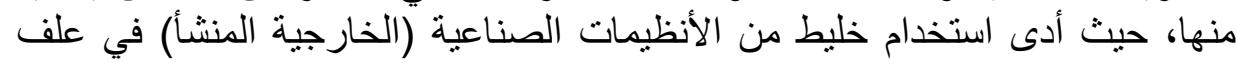

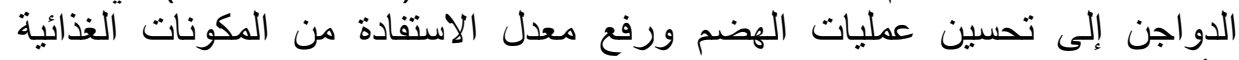

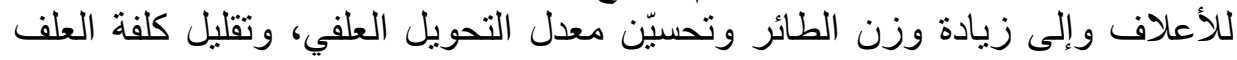

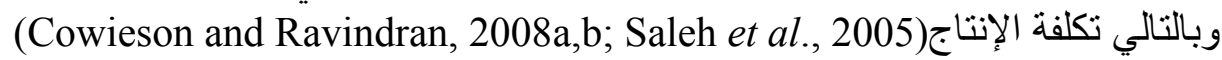
وجد الباحثون: (Jiang et al.(2008); Ghazi et al.(2003); Ritz et al.(1995) .Liu et al.(2008)

نتائج غير واضحة عند استخدام أنظيمات متعددة لها تأثيرات مميزة ، بينما

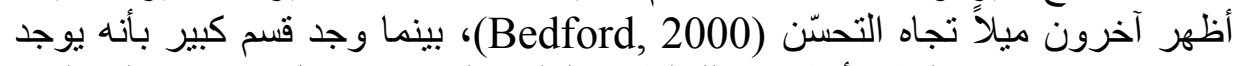

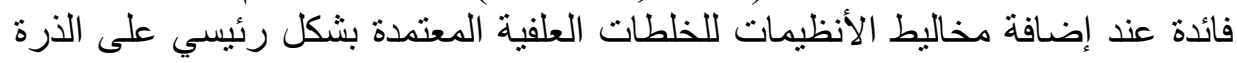
وكسبة فول الصويا، والتي تثكل غالبية مكونات الطاقة و البروتين لخلطات الدات الدو اجن. (Jiang et al., 2008; Cowieson and Ravindran,2008a; Zanella et al., 1999) بالرغم من أن الذرة ذات قيمة غذائية عالية وثابتة، فلربما لا نستفيد من إضافة الإنة

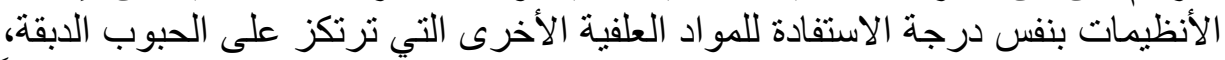

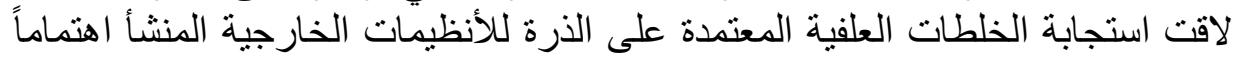
يؤخذ بعين الاعتبار نتيجة زيادة الضغط على أخصائي التغذية نتيجة ارتفاع أسعار النيار 
المواد المكونة للعلف (Cowieson and Ravindran, 2008a)، ولقد أظهرت

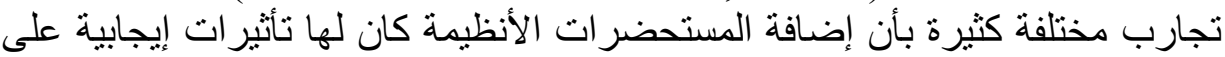

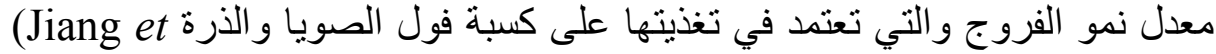
.al.,2008)

\section{MATERIALS and METHODS}

مـواد البحث وطرائقهـ

تم إجر اء التجربة في وحدة أبحاث تغذية الدواجن في قسم الإنتاج الحيواني في

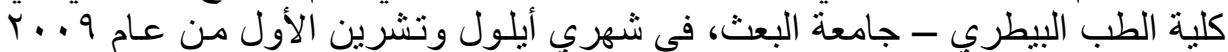

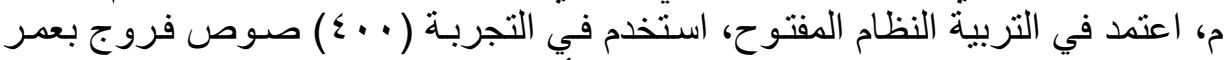

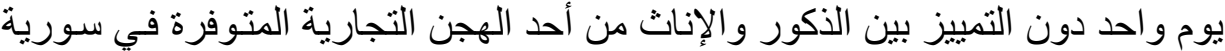

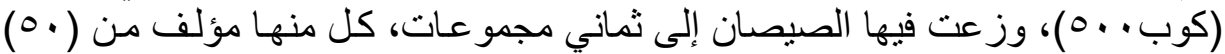

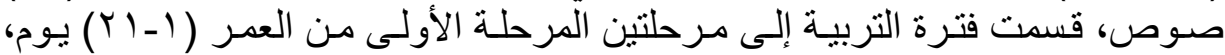

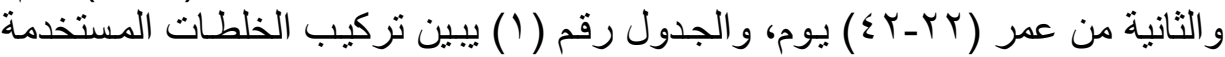

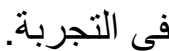

الخلطات العلفية: تم تركيب ثمانية خلطات علفية نباتية، لكل مرحلة من مر احل التربيـة،

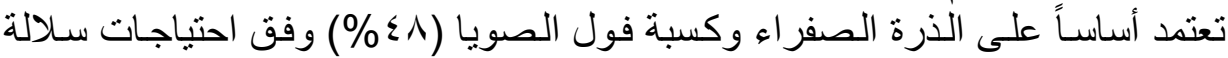

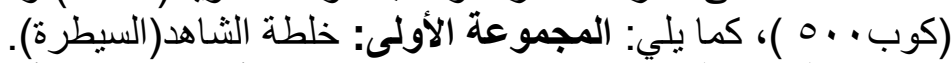

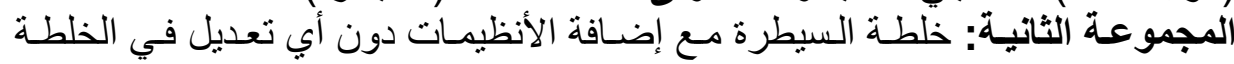

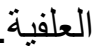
المجموعة الثالثة: خلطة السيطرة مع تخفيض الطاقة (10) كيلو كالوري دون إضـافة

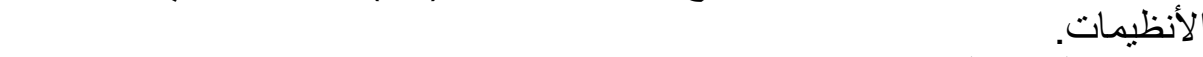
المجموعة رابعة: خلطة السيطرة مـع تخفيض الطاقـة(70) كيلو كـالوري مـع إضـافة

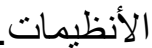

المجموعـة الخامسسة: خلطـة السيطرة مـع تخفيض الفوسفور (1. ·) \% دون إضـافة الأنظيمات.

المجموعـة السـادسة: خلطـة السيطرة مـع تخفيض الفوسـفور (1. · ) \% مـع إضـافة الأنظيمات. الفوسفور(0.1) \% دون إضافة الأنظيمات.

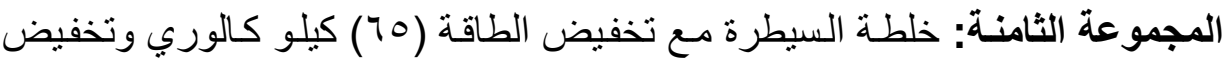
الفوسفور (0.1) \% مع إضافة الأنظيمات.

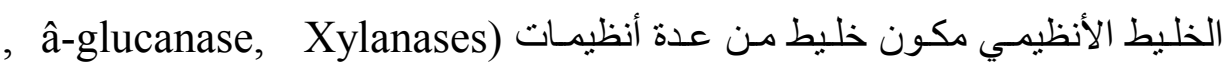
(Pectinases, Mannanases, Phytase حيث تم إضافة ( (0) غ غ من هذا الخليط. 


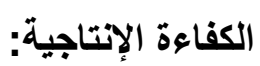

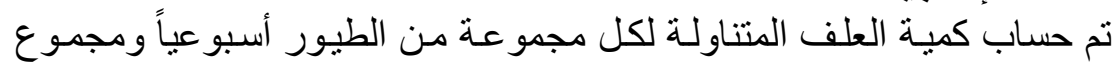

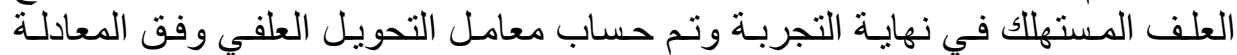

الآتية: - 20 - n

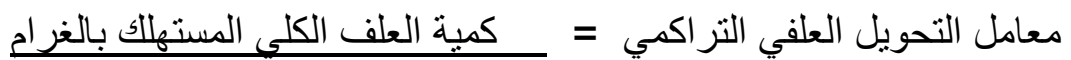
مجموع الزيادة في الوزن للطفي الكلئر بالغرام بالغر

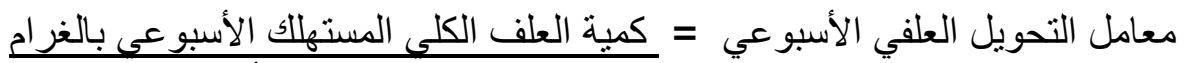

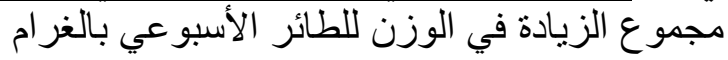

الجدول رقم ا: تركيب الخلطات العلفية لمرحلة التربية الأولى ( ـ ا (Y) يوماً:

\begin{tabular}{|c|c|c|c|c|}
\hline G4 & G3 & $\mathrm{G} 2$ & G1 & المادة/المجمو عة \\
\hline OAV.r & OAV.r & OVY.Y & OVY.Y & ذرة \\
\hline$r \leqslant 9 . \wedge$ & $r \leqslant 9 . \wedge$ & ror.q & ror.9 & صويا ع^§\% \\
\hline TY. & TY. & TY. & TY. & ثنائي فوسفات الكالسيوم ^| \% \\
\hline 11.0 & 11.0 & 11.0 & 11.0 & حجر كلسي \\
\hline .9 . & .9 . & .9. & .9 & لايسين \\
\hline r.r & T.r & T.r & r.r & مثيونين \\
\hline Y. & Y. 7 & Y. 7 & Y. 7 & ملح طعام \\
\hline IV.A & IV.A & rq.1 & rq.^ & زيت الصويا \\
\hline r. 9 & r. 9 & r. 9 & r. 9 & بيكربونات الصوديوم \\
\hline.$V$ &.$V$ & $\because V$ & $\because V$ & كولين كلور ايد \\
\hline 1 & 1 & 1 & 1 & فيتامينات ومعادن \\
\hline .0 & $\because .0$ & .0 & $\because 0$ & مضناد سموم فطرية \\
\hline$\because .0$ & $\because .0$ & $\because .0$ & $\because .0$ & مضناد كوكسيديا \\
\hline. .0 & - & $\because 0$ & - & الأنظيمات \\
\hline
\end{tabular}

الجدول رقم ب: تركيب الخلطات العلفية لمرحلة التربية الأولى (1-1) يوماً:

\begin{tabular}{|c|c|c|c|c|}
\hline G8 & G7 & G6 & G5 & المادة/المجمو عة \\
\hline $09 . .0$ & $09 \cdot .0$ & $0 \vee 7.0$ & $0 \vee 7.0$ & ذرة \\
\hline$r \leqslant 9.0$ & $r \leqslant 9.0$ & ro1.7 & ro1.7 & صويا ع>\&\% \\
\hline 17.7 & 17.7 & 17.7 & 17.7 & ثنائي فوسفات الكالسيوم ^\\
% \\
\hline $10 . r$ & 10.1 & $10 . r$ & $10 . r$ & حجر كلسي \\
\hline .9 . & .9. & .9 . & $\because 9$. & لايسين \\
\hline r.r & r.r & r.r & r.r & مثيونين \\
\hline Y. & r. & r. & r. 7 & ملح طعام \\
\hline 17.8 & 17.8 & r^. 7 & Y^.7 & زيت الصويا \\
\hline$r .9$ & r. 9 & r.9 & r.9 & بيكربونات الصوديوم \\
\hline
\end{tabular}


Assiut Vet. Med. J. Vol. 58 No. 132 January 2012

\begin{tabular}{|c|c|c|c|c|}
\hline.$V$ &.$V$ & $\cdot . V$ & $\cdot V$ & كولين كلور ايد \\
\hline 1 & 1 & 1 & 1 & فيتامينات ومعادن \\
\hline. .0 & .0 & $\because .0$ & $\because .0$ & مضناد سموم فطرية \\
\hline$\because .0$ & .0 & $\because .0$ &. .0 & مضاد كوكسيديا \\
\hline$\because .0$ & - & $\because 0$ & - & الأنظيمات \\
\hline
\end{tabular}

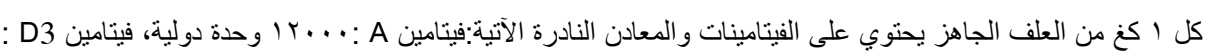

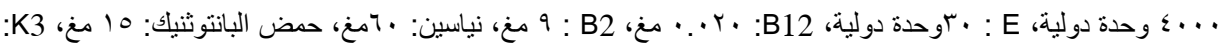

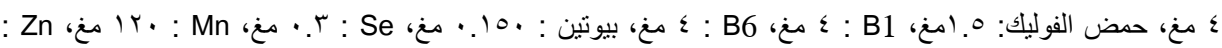

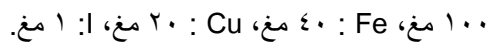

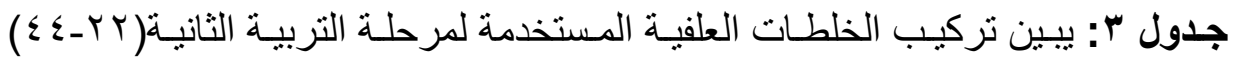
يوماً:

\begin{tabular}{|c|c|c|c|c|}
\hline G4 & G3 & G2 & G1 & المادة/المجمو عة \\
\hline $7 \leq 0.00$ & $7 \leqslant 0.7$ & $7 \Gamma 1.0$ & 7TI.1 & ذارة \\
\hline rqะ. & Yqะ.ร & rqV & rqV & صويا ص^ع\% \\
\hline $19 . r$ & $19 . r$ & $19 . r$ & $19 . r$ & ثنائي فوسفات الكالسيوم ^ \\
% \\
\hline 1. 9 & $\wedge .9$ & 1. 9 & 1. 9 & حجر كلسي \\
\hline$\because Y$ & $\cdot r$ & $\cdot r$ & $\cdot r$ & لايسين \\
\hline Y. & Y. & Y. & Y. & مثيونين \\
\hline $1 . V$ & $1 . V$ & $1 . V$ & $1 . V$ & ملح طعام \\
\hline TY.V & TY.V & $r \varepsilon .7$ & $r \varepsilon .7$ & زيت الصويا \\
\hline T.O & Y.o & Y.O & Y.o & بيكربونات الصوديوم \\
\hline .7 & .7 & .7 & .7 & كولين كلور ايد \\
\hline 1 & 1 & 1 & 1 & فيتامينات ومعادن \\
\hline$\because 0$ & .0 & $\because 0$ & .0 & مضاد سموم فطرية \\
\hline$\because 0$ & $\because 0$ & $\because 0$ & $\because 0$ & مضـاد كوكسيديا \\
\hline. .0 & - & $\because .0$ & - & الأنظيمات \\
\hline
\end{tabular}

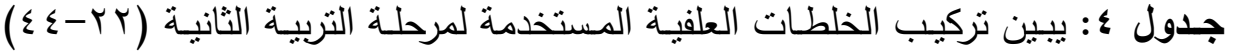
يوماً:

\begin{tabular}{|c|c|c|c|c|}
\hline G8 & G7 & G6 & G5 & المادة/اللجمو عة \\
\hline 701.10 & 701.9 & 740.10 & THO.Y & ذذرة \\
\hline r91.9 & r91.9 & r97.\& & r97. ६ & صويا 1^§\% \\
\hline IT.Y & $1 T .4$ & IT.Y & $1 T .4$ & كالسيوم ثنائي الفوسفور 1/1\% \\
\hline IY.A & Ir.A & IT.A & IT.A & حجر كلبي \\
\hline$\cdot . \mathrm{r}$ & $\cdot . r$ & $\cdot . r$ & $\cdot . r$ & لايسين \\
\hline T.Y & Y.Y & T.Y & Y.Y & مثيونين \\
\hline $1 . \mathrm{V}$ & $1 . \mathrm{V}$ & $1 . V$ & $1 . V$ & 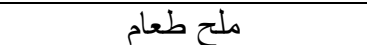 \\
\hline Y) & YI & YY.V & YT.V & زيت الصويا \\
\hline
\end{tabular}




\begin{tabular}{|c|c|c|c|c|}
\hline Y.o & T.O & Y.o & Y.o & بيكربونات الصوديوم \\
\hline .7 & .7 &. .7 &. .7 & كولين كلور ايد \\
\hline 1 & 1 & 1 & 1 & فيتامينات ومعادن \\
\hline .0 & .0 & .0 & .0 & مضناد سموم فطرية \\
\hline .0 & .0 & $\because 0$ & .0 & مضناد كوكسيديا \\
\hline. .0 & - & $\because 0$ & - & الأنظيمات \\
\hline
\end{tabular}

كل ا كغ من العلف الجاهز يحتوي على الفيتامينات والمعادن النادرة الآتية: فيتامين A : .... . . وحدة دولية،

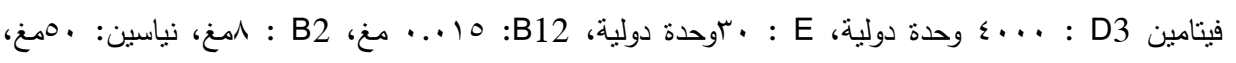

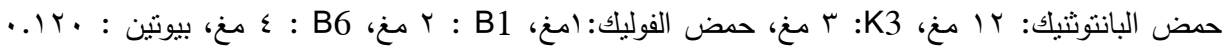

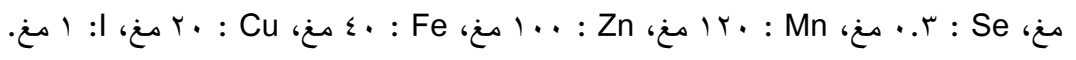

جدول رقم •: القيم الغذائية المحسوبة للخلطـات العلفيـة في المرحلة الأولى ( - (ب)

\begin{tabular}{|c|c|c|c|c|}
\hline G4 & G3 & G2 & G1 & التحليل/ المجمو عة \\
\hline r... & r... & T.70 & $r .70$ & طاقة لك.ك/كغ \\
\hline Yr.P & Yr. $\cdot r$ & $r r^{\prime} \cdot r$ & $T^{T} \cdot{ }^{\prime}$ & بروتين \\
\hline ITY.YY & ITY.YY & 119.17 & 119.17 & $\mathrm{C} / \mathrm{P}^{*}$ \\
\hline r.M & T.M & T.MI & r.M & ألياف\% \\
\hline$r . V T$ & Y.VY & מוז & מת & الدهن الخام\%\% \\
\hline 1.04 & 1.04 & 1.04 & 1.04 & لايسين\% \\
\hline $.0 \mathrm{~V}$ & $.0 \mathrm{~V}$ & $.0 \mathrm{~V}$ & $.0 \mathrm{~V}$ & مثيونين\% \\
\hline$\cdot .9$ & .9 & .9 & $\because .9$ & مثيونين +سيستين\% \\
\hline 1 & 1 & 1 & 1 & كالسيوم\% \\
\hline $.7 \pi$ & .74 &.$V 7$ & $\therefore$. & فوسفور كلي \% \\
\hline. ro &. ro &.$\leqslant 0$ &.$\leqslant 0$ & فوسفور ممتص\% \\
\hline$\because r$. &.$r$. & $\because r$. & $\because r$. & صوديوم\% \\
\hline$\cdot r$ & $\cdot r$ &.$r$ & $\cdot r$ & كلور \% \\
\hline
\end{tabular}

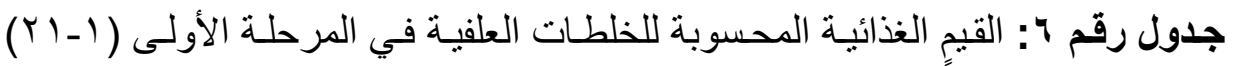
بوراً:

\begin{tabular}{|c|c|c|c|c|}
\hline G8 & G7 & G6 & G5 & التحليل/ المجموعة \\
\hline r... & r... & r. 70 & T.70 & طاقة ME ك.ك/كغ \\
\hline$r r_{.} \cdot r$ & $r r_{.} \cdot r$ & Yr. $\cdot$ r & $r r_{.} \cdot r$ & بروتين \\
\hline & & 119.17 & 119.17 & $\mathrm{C} / \mathrm{P} *$ \\
\hline r.r. & r.r. & r. rq & r. rq & ألياف\% \\
\hline Y.TV & Y.TV & r. r & r. r & الدهن الخام\% \\
\hline 1.04 & 1.04 & 1.04 & 1.04 & لايسين\% \\
\hline. $.0 \mathrm{~V}$ &. $.0 \mathrm{~V}$ & $.0 \mathrm{~V}$ & $.0 \mathrm{~V}$ & مثيونين\% \\
\hline
\end{tabular}

$\wedge$ 
Assiut Vet. Med. J. Vol. 58 No. 132 January 2012

\begin{tabular}{|c|c|c|c|c|}
\hline$\cdot .9$ & $\cdot .9$ &. .9 & $\cdot .9$ & مثيونين +سيستين\% \\
\hline 1 & 1 & 1 & 1 & كالسيوم\% \\
\hline $.7 \pi$ & . & $\because \mathrm{VO}$ & $\because$ Vo & فوسفور كلي \% \\
\hline o & • & $\cdot . \leqslant 0$ & $\because \leqslant 0$ & فوسفور ممتص\% \\
\hline$\cdot r \cdot$ & $\cdot r \cdot$ & $\cdot r \cdot$ & $\because r$. & صوديوم\% \\
\hline.$r$ &.$r$ &..$r$ &.$Y$ & كلور \% \\
\hline
\end{tabular}

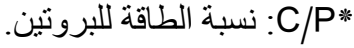

جدول رقم V: القيم الغذائية المحسوبة للخلطات العلفية في المرحلة الثانية (r ب-؟ ؟) يوماً:

\begin{tabular}{|c|c|c|c|c|}
\hline G4 & G3 & G2 & G1 & التحليل/ المجمو عة \\
\hline ए... & ए।.. & 4170 & 1170 & طاقة ME ك.ك/كغ \\
\hline $19 . V \mathrm{~V}$ & $19 . \mathrm{VV}$ & $19 . V V$ & $19 . \mathrm{VV}$ & بروتين\%\% \\
\hline $101 . \wedge 4$ & $101 . \wedge r$ & $17 . .1$ & $17 . .1$ & $\mathrm{C} / \mathrm{P}$ \\
\hline Y.OV & r.OV & r.00 & r.00 & ألياف\% \\
\hline r.00 & 5.00 & 5.10 & 4.10 & الدهن الخام\%\% \\
\hline I. TV & $1 . r V$ & $1 . r V$ & $1 . r V$ & لايسين\% \\
\hline .04 & .04 & .04 & .04 & مثيونين\% \\
\hline. .10 & .10 &. .10 & .10 & مثيونين +سيستين\% \\
\hline$\cdot .9$ & $\cdot .9$ & $\cdot .9$ & $\cdot .9$ & كالسيوم\% \\
\hline$\cdot . \wedge$ & $\cdot .1$ &. .1 & $\cdot . \wedge$ & فوسفور كلي \% \\
\hline$\cdot \leqslant \leqslant$ & 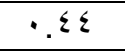 & 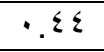 & $\cdot \varepsilon \leqslant$ & فوسفور ممتص\%\% \\
\hline. .10 &. .10 &. .10 &. .10 & صوديوم\% \\
\hline. .10 &. .10 &. .10 &. .10 & كلور \% \\
\hline
\end{tabular}

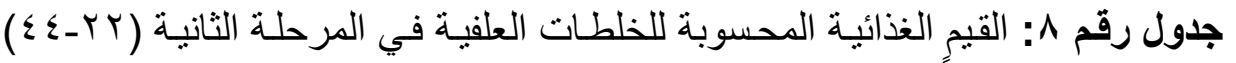
يوماً:

\begin{tabular}{|c|c|c|c|c|}
\hline G8 & G7 & G6 & G5 & التحليل/ المجمو عة \\
\hline T1.. & r)... & $r 170$ & 1170 & طاقة ME \\
\hline $19 . V V$ & $19 . V V$ & $19 . V \mathrm{~V}$ & $19 . V \mathrm{~V}$ & بروتين\% \\
\hline $10 \Lambda .1 \mu$ & 101.14 & $17 . .1$ & $17 . .1$ & $\mathrm{C} / \mathrm{P}^{*}$ \\
\hline Y.OV & Y.OV & r.00 & r.00 & ألباف\% \\
\hline$Y \leqslant V$ & $Y \leqslant V$ & $\Gamma .10$ & 5.10 & الدهن الخاحه\% \\
\hline $1 . r V$ & $1 . r V$ & $1 . r V$ & $1 . Y V$ & لايسين\%\% \\
\hline .04 & .04 & .04 & .04 & مثيونين\% \\
\hline$\cdot .10$ & $\cdot .10$ &. .10 &. .10 & مثيونين +سيستين\% \\
\hline
\end{tabular}




\begin{tabular}{|c|c|c|c|c|}
\hline$\cdot .9$ & $\cdot .9$ & .9 & $\cdot .9$ & كالسيوم\%\% \\
\hline .77 &. .77 &. .77 & $\cdot .77$ & فوسفور كلي \% \\
\hline$\cdot r \varepsilon$ &.$\Gamma \xi$ &.$\Gamma \varepsilon$ &.$r \varepsilon$ & فوسفور ممنص\% \\
\hline .10 & .10 & .10 & .10 & صوديوم\%\% \\
\hline .10 & .10 & .10 & .10 & كلور \% \\
\hline
\end{tabular}

\section{RESULTS}

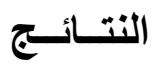

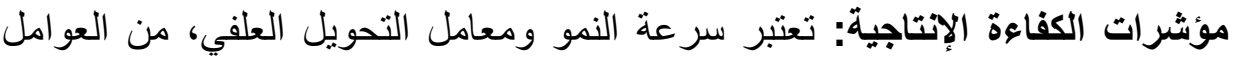

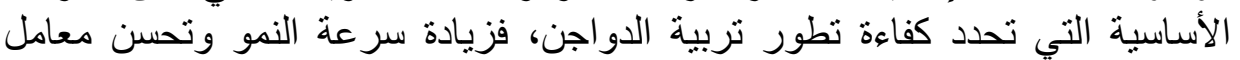

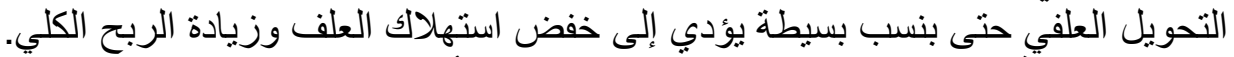

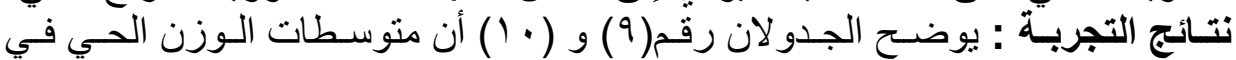

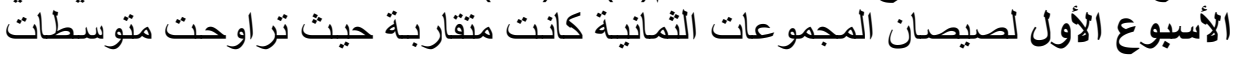

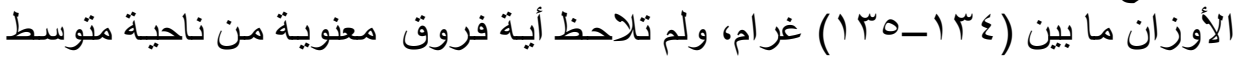

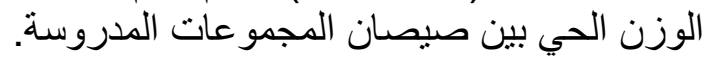

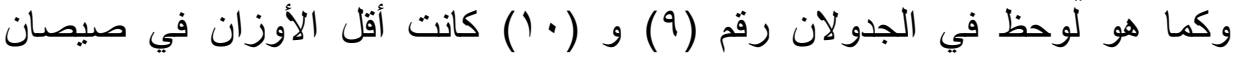

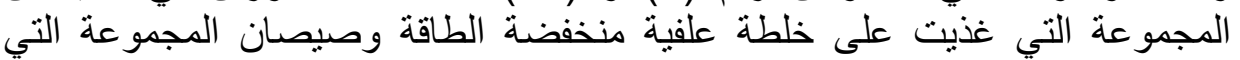

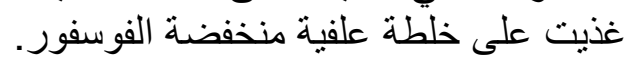

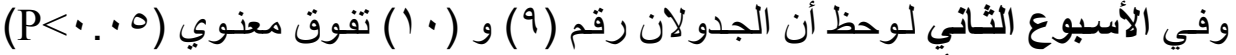

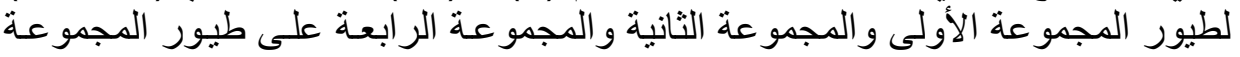

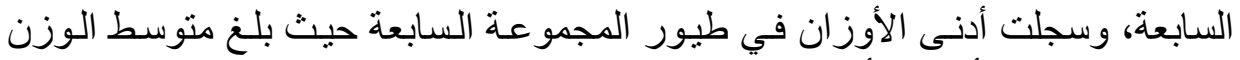

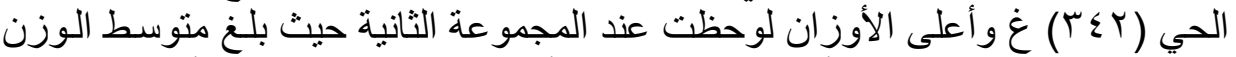

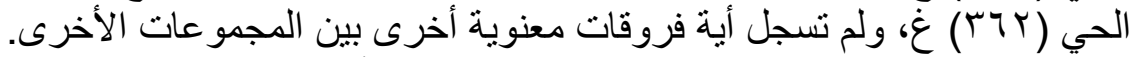

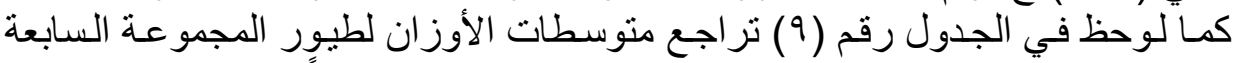

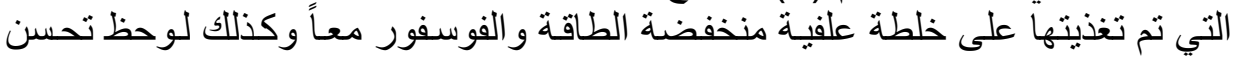
متوسط الوزن الحي في طيور المجموعات التي تم تغذيتها عل خلطة علفية التونة أضيف إليها

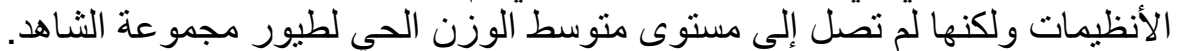

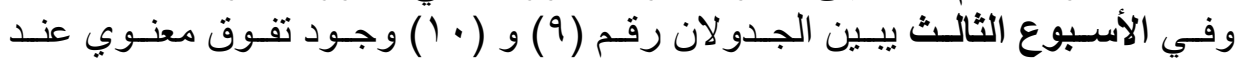

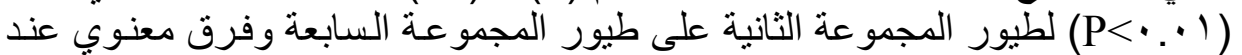

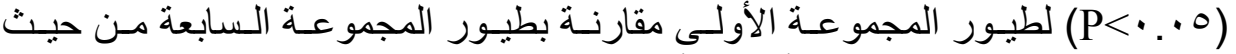

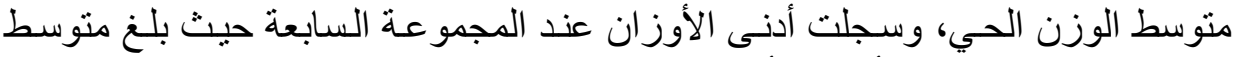

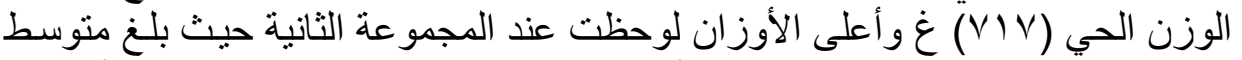

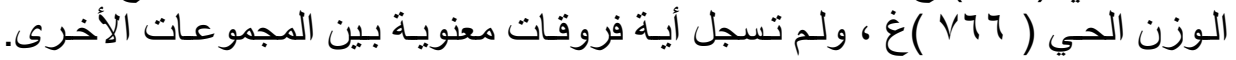

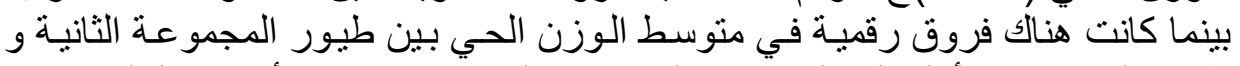

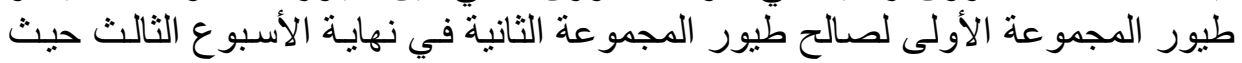




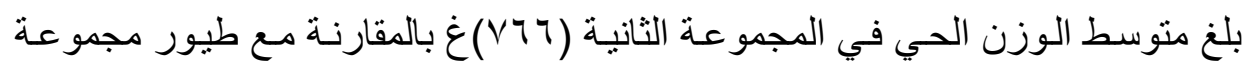

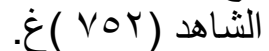

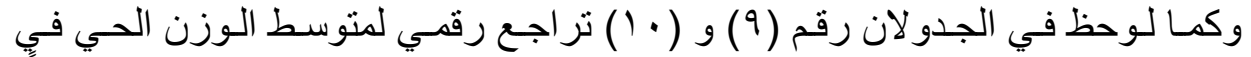

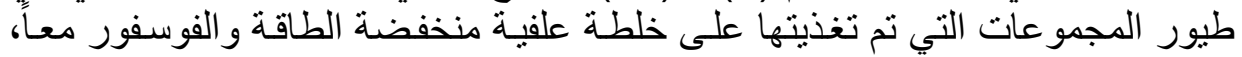

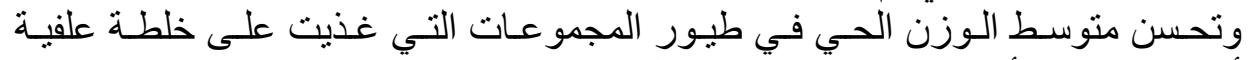

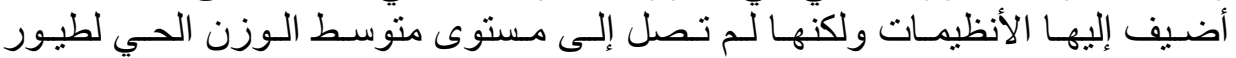

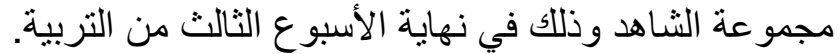

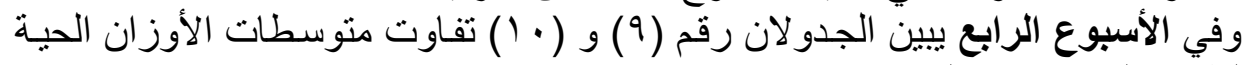

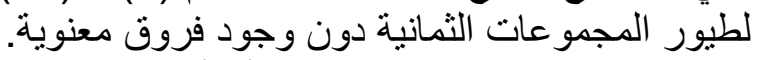

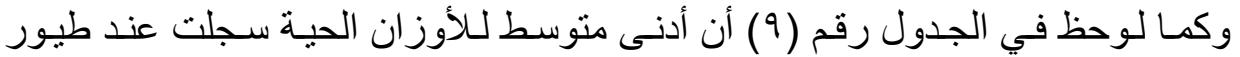

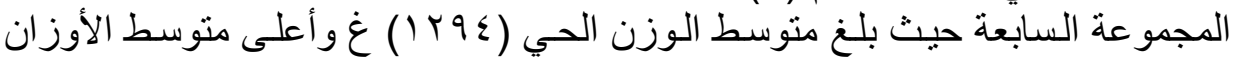

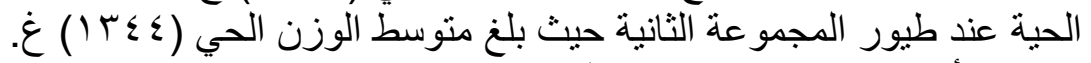

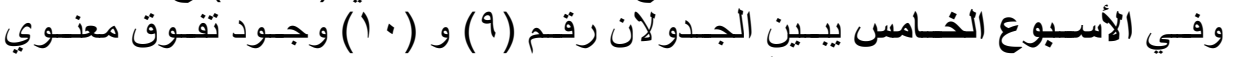

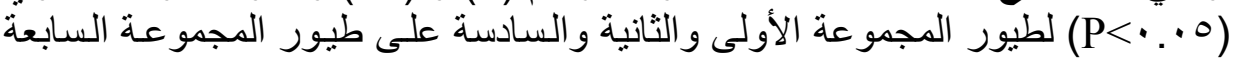

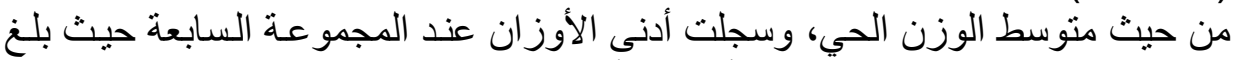

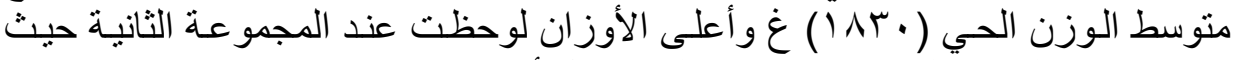

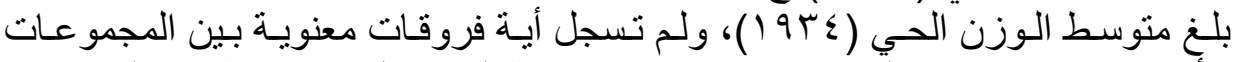

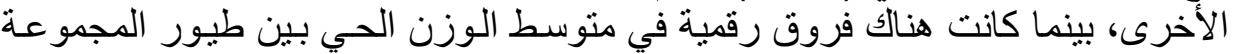

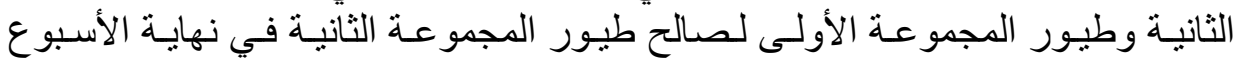

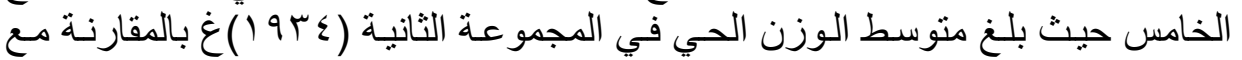

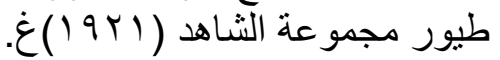

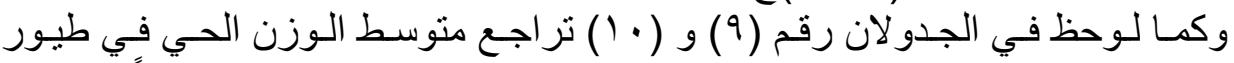

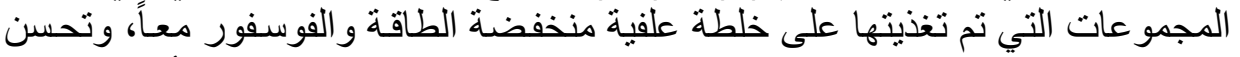

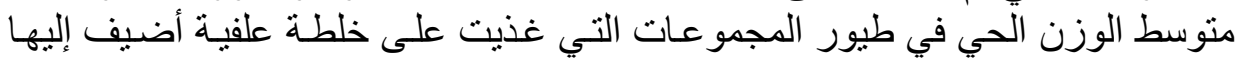

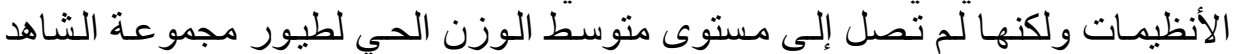
وذللك في نهاية الأسبوع الخامس من التربية. وفي الأسبوع السادس يبين الجدو لان رقم (9) و ( • (1) وجود تفوق معنوي (0 . . • (P)

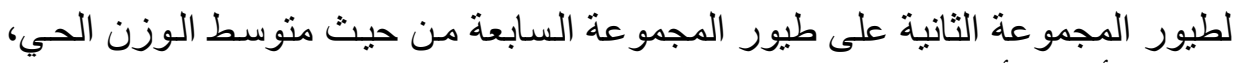

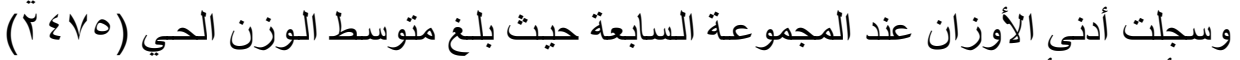

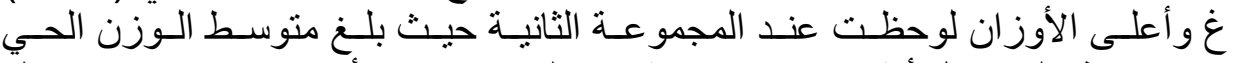

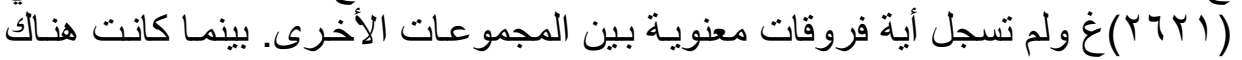

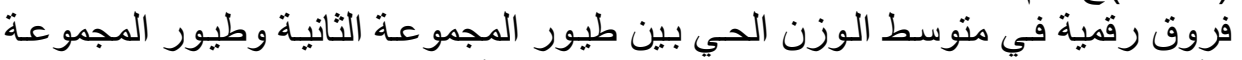

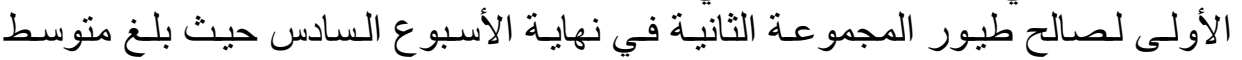

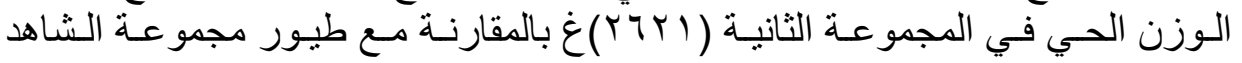
(Y०9r)

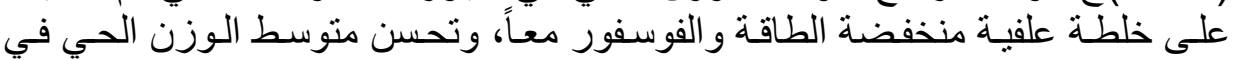


طيور المجموعات التي غذيت على خلطة علفية أضيف إليها الأنظيمات ولكنها لم تصل إلى مستوى متوسط الوزن الحي لطيور مجمو عة الثـاهد.

جدول رقم 9: يبين المتوسطات الحسابية لأوزان الطيور الحيـة الأسبوعي في التجربـة

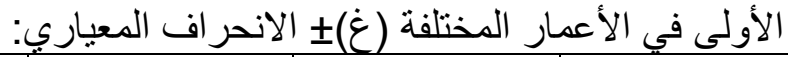

\begin{tabular}{|c|c|c|c|c|}
\hline المجمو عة؛ & المجمو عة" & المجمو عة r & المجموعة | & \\
\hline تخفيض أنظيم الطاقة- & تخفيض الطاقة_10 & أنظيمات & شاهد & الأسبوع \\
\hline $\begin{array}{l}1 \% 0 \\
1 \leq . \wedge \pm\end{array}$ & $\begin{array}{l}1 T \varepsilon \\
1 N . r \pm\end{array}$ & $\begin{array}{l}140 \\
1 . .5 \pm\end{array}$ & $\begin{array}{l}1 \% 0 \\
1 \leq .4 \pm\end{array}$ & 1 \\
\hline $\begin{array}{l}r 01 \\
r v_{ \pm}\end{array}$ & $\begin{array}{l}r \leqslant q \\
r r \pm\end{array}$ & $\begin{array}{l}\text { arty } \\
\text { rut }\end{array}$ & $\begin{array}{l}\text { ary. } \\
\varepsilon r \pm \pm\end{array}$ & $r$ \\
\hline $\begin{array}{l}V \leqslant V \\
7 \Lambda .1 \pm\end{array}$ & $\begin{array}{l}V \% \Lambda \\
V 9.0 \pm\end{array}$ & $\begin{array}{l}\text { AV74 } \\
11.0 \pm\end{array}$ & $\begin{array}{l}{ }^{a} \text { VOY } \\
\wedge r . \wedge \pm\end{array}$ & $r$ \\
\hline $\begin{array}{l}\text { ITr } \\
\text { IrTE }\end{array}$ & $\begin{array}{l}\text { IrIV } \\
\text { Irot }\end{array}$ & $\begin{array}{l}1 T \leq \varepsilon \\
1 T r \pm\end{array}$ & $\begin{array}{l}\text { Irry } \\
\text { IVYE }\end{array}$ & $\varepsilon$ \\
\hline $\begin{array}{l}191 \varepsilon \\
174 \pm\end{array}$ & $\begin{array}{l}\text { TAVE } \\
\text { MTYE }\end{array}$ & $\begin{array}{l}\text { a) } 94 \varepsilon \\
191 \pm\end{array}$ & $\begin{array}{l}\text { a)941 } \\
171 \pm\end{array}$ & 0 \\
\hline $\begin{array}{l}\text { TOVA } \\
\text { rNIE }\end{array}$ & $\begin{array}{l}\text { roTh } \\
\text { rA }\{ \pm\end{array}$ & $\begin{array}{l}\text { aYtri } \\
\text { rTYE }\end{array}$ & $\begin{array}{l}r 094 \\
r .9 \pm\end{array}$ & 7 \\
\hline
\end{tabular}

جدول رقم • 1: يبين المتوسطات الحسابية لأوزان الطيور الحية الأسبو عي في التجربـة

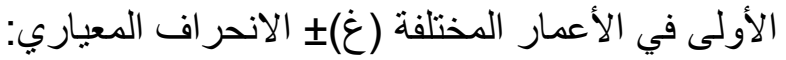

\begin{tabular}{|c|c|c|c|c|}
\hline المجمو عةم & المجمو عةلV & المجمو عةجا & المجمو عةه & \\
\hline تخفيض (الطاقة+الفوسفور) & تخفيض الطاقة+ & تخفيض الفوسفور + & الفوسفور & الأسبوع \\
\hline 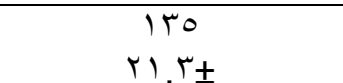 & $\begin{array}{l}1 \% \varepsilon \\
1 \wedge \Lambda_{+}\end{array}$ & 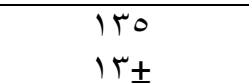 & $\begin{array}{l}1 \pi \varepsilon \\
1 \leqslant 9+\end{array}$ & 1 \\
\hline $\begin{array}{l}00 \\
r y \pm\end{array}$ & $\begin{array}{l}r \varepsilon r^{b} \\
r \wedge \pm\end{array}$ & $\begin{array}{l}\text { rov } \\
\varepsilon r \pm\end{array}$ & $\begin{array}{l}r \leqslant q \\
r o \pm\end{array}$ & $r$ \\
\hline $\begin{array}{l}V \leqslant r \\
V Y .0 \pm\end{array}$ & $\begin{array}{l}\mathrm{Bb} \vee \mathrm{V} \\
\Lambda \cdot .{ }^{\circ} \pm\end{array}$ & $\begin{array}{l}V \leqslant V \\
V r . V \pm\end{array}$ & $\begin{array}{l}V(Y) \\
T V . \wedge \pm\end{array}$ & r \\
\hline 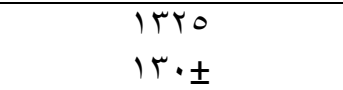 & $\begin{array}{l}\text { IrqE } \\
\text { MrE }\end{array}$ & $\begin{array}{l}1149 \\
11 \cdot \pm\end{array}$ & 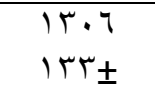 & $\varepsilon$ \\
\hline $\begin{array}{l}19 \cdot 1 \\
100 \pm\end{array}$ & $\begin{array}{l}\text { b) } 14 . \\
19 \leq \pm\end{array}$ & $\begin{array}{l}\text { a) } 911 \\
140 \pm\end{array}$ & $\begin{array}{l}1197 \\
197 \pm\end{array}$ & 0 \\
\hline 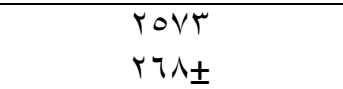 & $\begin{array}{l}\mathrm{b}_{Y} \leqslant V_{0} \\
r \cdot \varepsilon \pm\end{array}$ & $\begin{array}{l}\text { rovi } \\
\text { rqrE }\end{array}$ & $\begin{array}{l}\text { rOH } \\
\text { rlOE }\end{array}$ & 7 \\
\hline
\end{tabular}

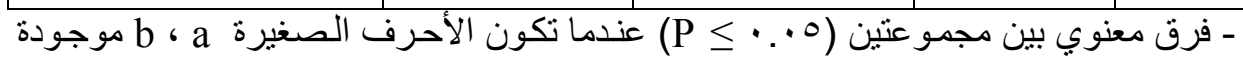
بنفس الصف بشكل مختلف. 


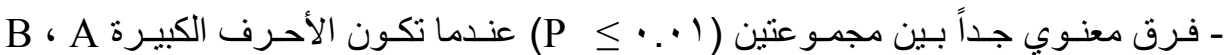
موجودة بنفس الصف بشكل مختلف.

\section{كمية العلف المستهلك ومعامل التحويل العلفي:}

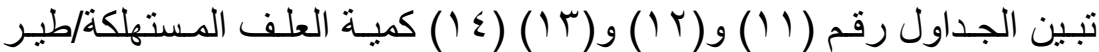

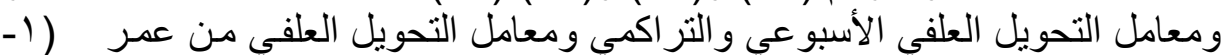

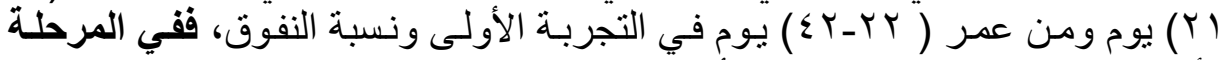

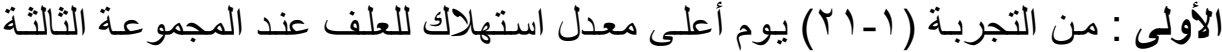

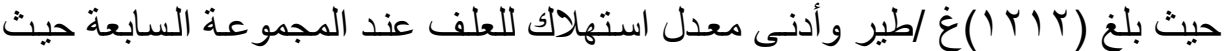

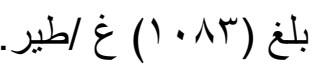

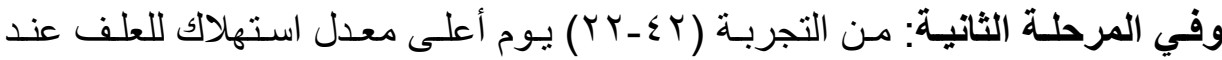

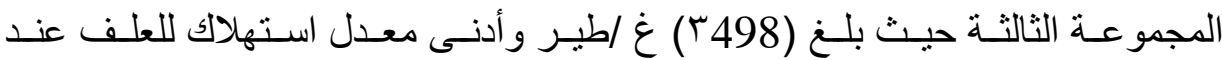

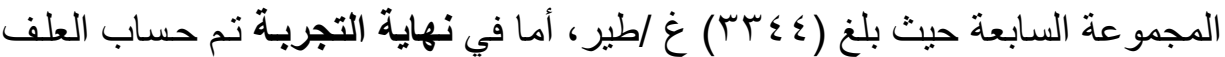

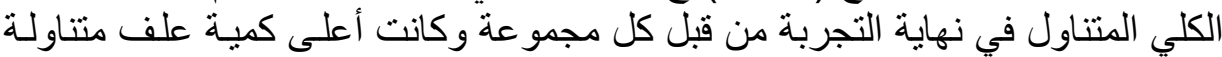

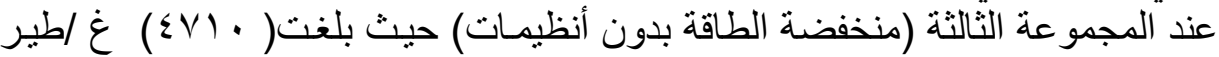

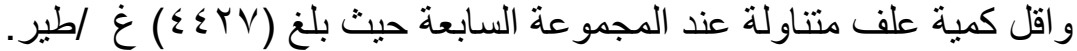

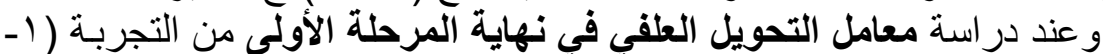

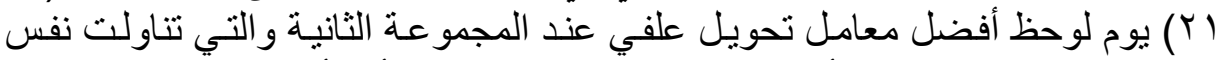

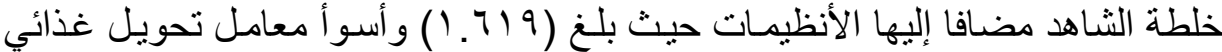

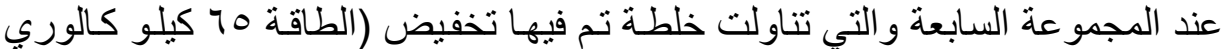

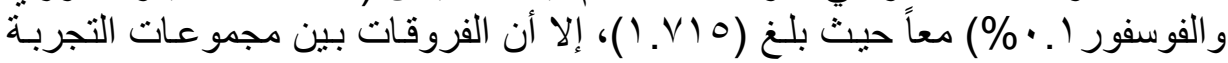
كانت بسيطة.

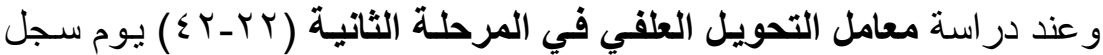

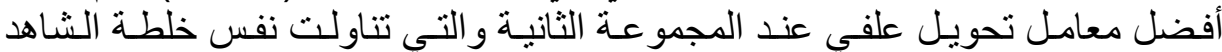

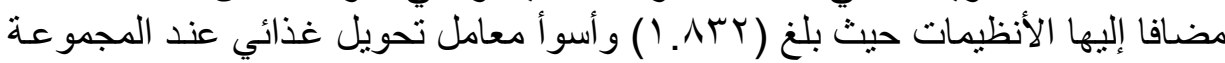

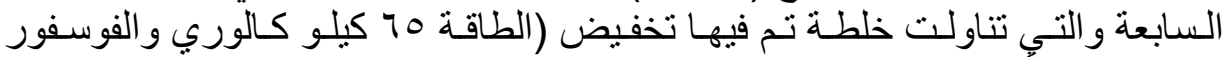

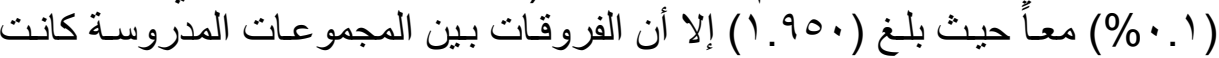

و عند دراسة معامل التحويل العلفي في نهاية التجربة بعمر ستة أسـابيع لوحظ

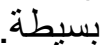

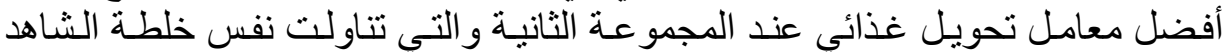

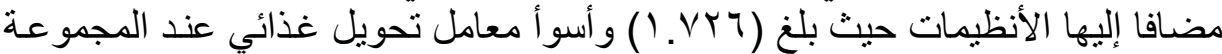

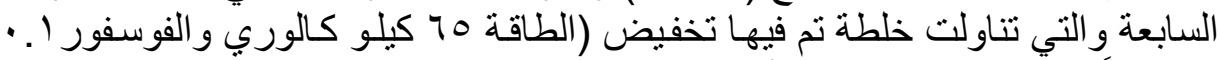

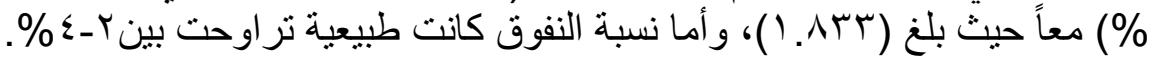

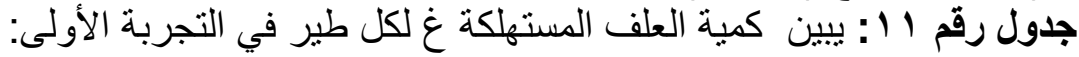

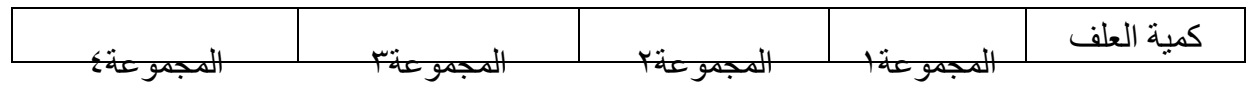


Assiut Vet. Med. J. Vol. 58 No. 132 January 2012

\begin{tabular}{|c|c|c|c|c|}
\hline تخفيض الطاقة- & تخفيض الطاقة_o7 & شاهد+أنظيمات & شاهد & \\
\hline $1 \leq 9$ & 101 & $1 \leq \Lambda$ & 10. & الأسبوع ا \\
\hline rvi & rVT & rv. & rvo & الأسبو ع r \\
\hline$T V$. & 710 & 779 & $T \vee 0$ & الأسبوع r \\
\hline $1 \cdot \leqslant r$ & $1.0 r$ & $1 . r q$ & $1 . \leqslant 0$ & الأسبوع ع \\
\hline 1.87 & 1.11 & 1.10 & $1 \cdot 1$. & الأسبوع م \\
\hline Irq & סדו"1 & $1 r \wedge 9$ & 1499 & الأسبو ع 7 \\
\hline 119. & ITIK & $111 \mathrm{~V}$ & Ir.. & مرحلة الأولى \\
\hline ए & $r \leq q \wedge$ & $r \varepsilon \cdot r$ & $r \leq r \leq$ & مرحلة الثانية \\
\hline$\leqslant 7.1$ & हV।. & $\leqslant 09$. & $\leq \pi Y \leqslant$ & التر اكمي \\
\hline
\end{tabular}

جدول رقم r ا : يبين كمية العلف المستهلكة غ لكل طير في التجربة الأولى:

\begin{tabular}{|c|c|c|c|c|}
\hline المجمو عةم & المجمو عةلV & المجمو عة77 & المجمو عةه & \\
\hline 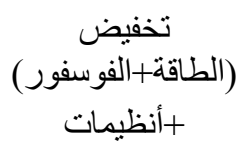 & تخفيض الطاقة+ & الفوسفور+أنظيضمات & تخفيض الفوسفور & كمية العلف \\
\hline 100 & 105 & $1 \leqslant 9$ & $1 \leqslant \Lambda$ & الأسبوع ا \\
\hline TVY & TVY & TVY & דצד & الأسبو ع r \\
\hline$O \wedge V$ & $00 \mathrm{~V}$ & TVT & Tצ & الأسبوع r \\
\hline$\Lambda \leqslant 7$ & 1.1 & $1 . \leqslant r$ & $1 . r V$ & الأسبو ع ع \\
\hline 1111 & 1.94 & $1 . V V$ & $1 \cdot V r$ & الأسبوع 0 \\
\hline $1 \leqslant \leqslant r$ & $1 \leqslant 0$. & IrqY & $|Y N|$ & الأسبو ع 7 \\
\hline $111 \varepsilon$ & 1.人 & $119 \varepsilon$ & 1187 & مرحلة الأولى \\
\hline$r \varepsilon .1$ & & $r \leqslant 1 T$ & q זr. & مرحلة الثانية \\
\hline$\leqslant 010$ & $\varepsilon \varepsilon r V$ & $\leqslant 7.7$ & 5077 & التر اكمي \\
\hline
\end{tabular}

جدول رقم بـ 1: يبين معامل التحويل العلفي الأسبو عي و التر اكمي ونسبة النفوق :

\begin{tabular}{|c|c|c|c|c|}
\hline المجمو عة؛ & المجمو عة" & المجمو عة ب & المجمو عة 1 & \\
\hline تخفيض أنظيمات & تخفيض الطاقة_r & شاهيمات & شـاهد & معامل التحويل \\
\hline 1.09 . & 1.74. & $1.0 \mathrm{VT}$ & 1.094 & الأسبوع| \\
\hline
\end{tabular}




\begin{tabular}{|c|c|c|c|c|}
\hline $1.77 \varepsilon$ & $1 . v \leq 9$ & 1.74. & $1.77 \mathrm{~V}$ & الأسبوع r \\
\hline I.VYr & 1.871 & 1.707 & I.VKT & الأسبوع r \\
\hline $1 . V \vee \wedge$ & I.AIV & I.V91 & $1 . \vee \wedge 9$ & الأسبو ع ع \\
\hline 1. Aor & $1.9 \leq 1$ & I.NKr & $1 . \wedge \leq 7$ & الأسبوع • \\
\hline $1.9 \leqslant V$ & 1.978 & $1 . \wedge \vee 7$ & 1.94 & الأسبوع 7 \\
\hline 1.709 & 1.21. & 1.719 & 1.771 & مرحلة الأولى \\
\hline 1.109 & $1.9 \cdot 1$ & וגני & 1.107 & مرحلة الثانية \\
\hline 1.209 & 1.1 .9 & I.VYY & 1.201 & التر اكمي \\
\hline$\% \varepsilon$ & $\% \varepsilon$ & $\% r$ & $\% r$ & نسبة النفوق \\
\hline
\end{tabular}

جدول رقم \& ا : يبين معامل التحويل العلفي الأسبو عي و التر اكمي ونسبة النفوق في

\begin{tabular}{|c|c|c|c|c|}
\hline المجموعة & المجموعة & المجمو عة & المجمو عة & \\
\hline 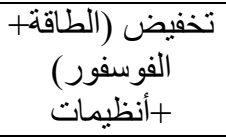 & تخفيض الطاقة++ & تخفيض الفوسفور & تخفيض الفوسفور & معامل التحويل \\
\hline 1.011 & $1.7 \cdot r$ & 1.09. & $1.7 \cdot r$ & الأسبوع| \\
\hline 1.790 & 1.87. & $1.7 \times 7$ & $1 . V \cdot r$ & الأسبوعr \\
\hline 1.VT & I.VAI & $1 . V Y T$ & אTV 1. & الأسبوع r \\
\hline I.VAV & $1 . \wedge \cdot 1$ & $1 . V 9 r$ & r. & الأسبوع ء \\
\hline $1 . \wedge \leqslant \vee$ & 1.997 & 1.101 & 1.911 & الأسبوع • \\
\hline $1.9 \leq v$ & $r_{.} .0 \varepsilon$ & 1.901 & 1.947 & الأسبوع 7 \\
\hline $1.7 V T$ & 1.110 & $1.77 \varepsilon$ & $1.7 \times 9$ & مرحلة الأولى \\
\hline $1 . \wedge 71$ & 1.90. & $1 . \wedge 7 V$ & $1 . \wedge \wedge$. & مرحلة الثانية \\
\hline 1.VTV & سזג.1 & 1.870 & I.V^. & التر اكمي \\
\hline$\% r$ & $\% Y$ & $\% Y$ & $\% Y$ & نسبة النفوق \\
\hline
\end{tabular}

\section{DISCUSSION}

\section{المناقشة}

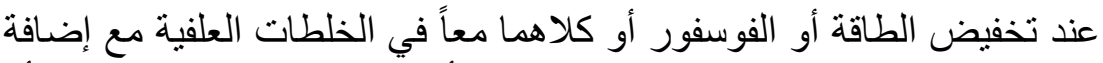

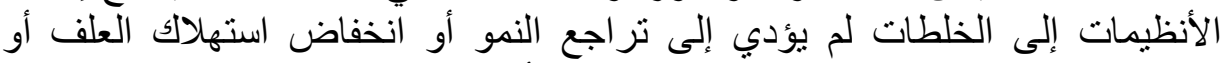

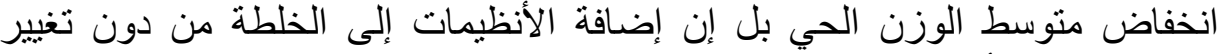
قيمتها الغذائية أدى إلى تحسن المعايير السابقة، ولم تلاحظ فروق معنوية ما بين 
متوسط الوزن الحي للأعمار المختلفة بين المجموعات التي أضيف لها الأنزيم بالمقارنة مع مجموعة الشاهد أو المجموعات التي تم تخفيض نسبة الطاقة و الفوسفور

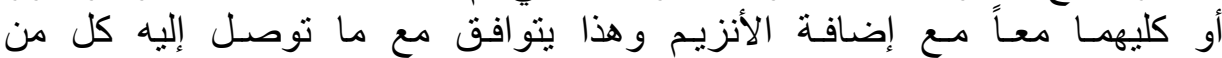

Rutherfurd et al. (2007); Maisonnier (2004)

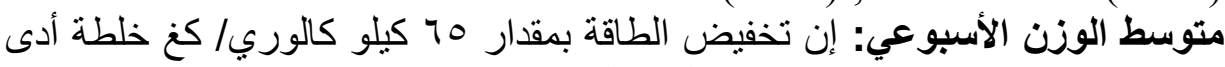

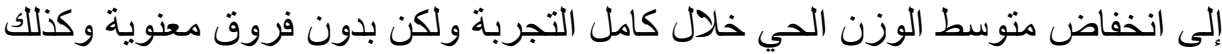

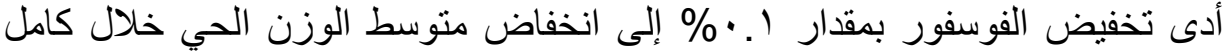
التجربة ولكن بدون فروق معنوية.

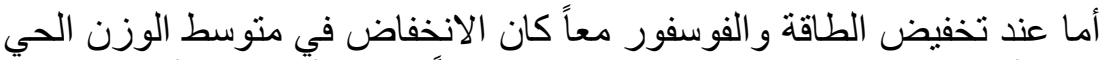

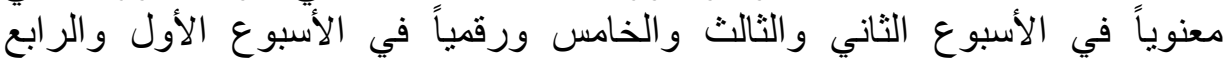

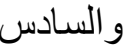
لوحظ عند إضافة الأنظيمات إلى الخلطات العلفية منخفضة الطاقة و الفوسفور

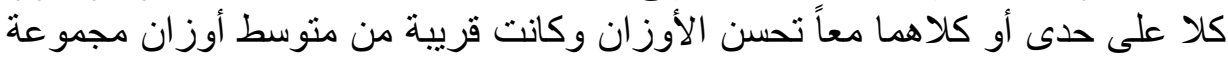

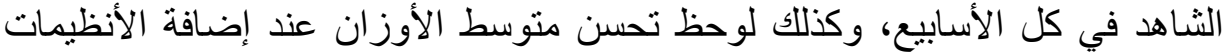

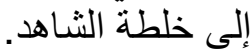

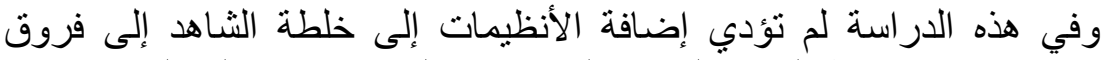

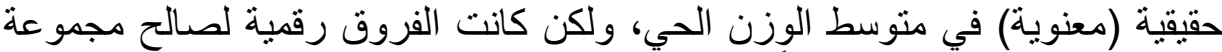

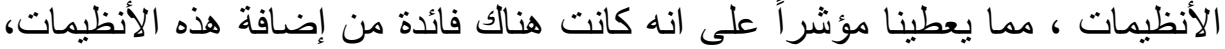

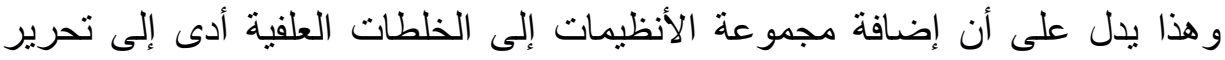

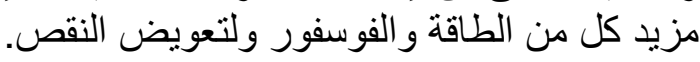

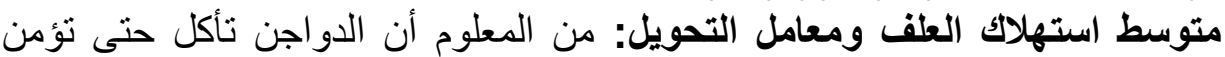

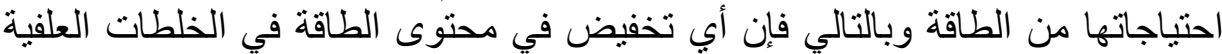

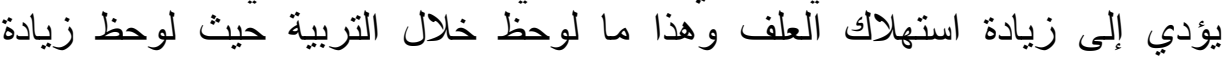

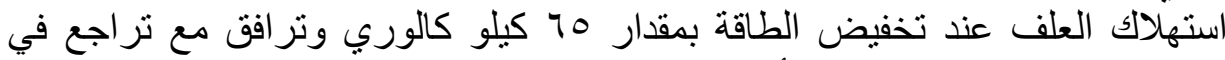
معامل التحويل و عند إضافة الأنظيمات لوحظ انخفاض في استهلاك العلف مع مع تحسن

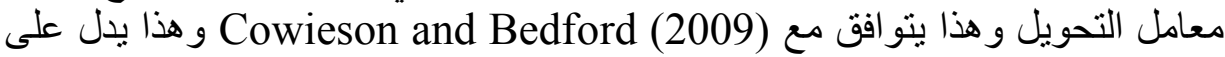

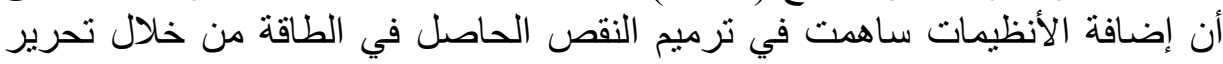

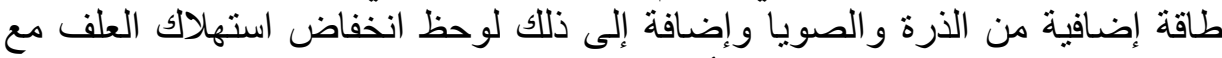

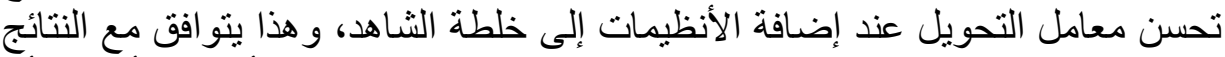

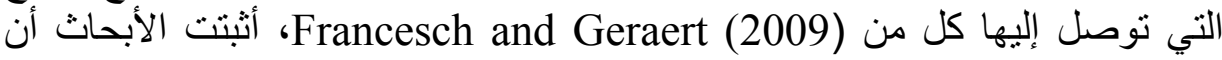

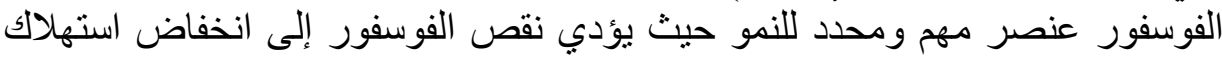
العلف وتراجع في النمو ومعامل التحويل وفي بحثنا هذا لوحظ انخفاض الفت استهلاك

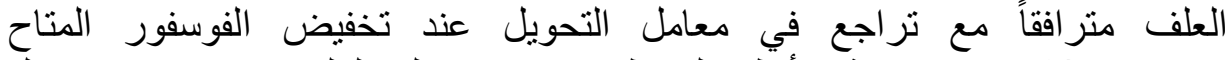

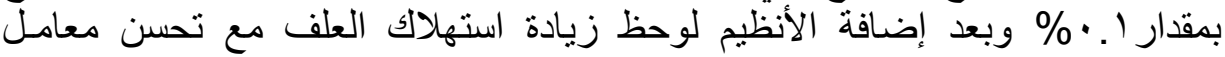

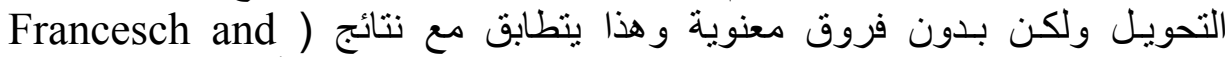

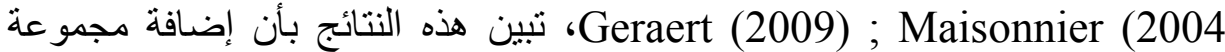
الأنظيمات بسمح لمنتجي الأعلاف وأخصائي التغذية في تخفيض مستوى الفوسفور 


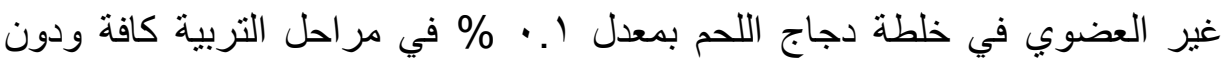

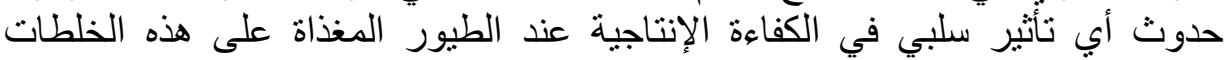

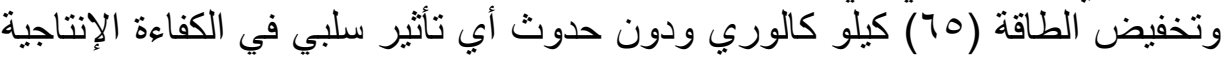
و هذا يتو افق مع كل من (2009) Francesch and Geraert.

\section{CONCLUSIONS and RECOMMENDATIONS}

\section{الاستنتاجات والتوصيات}

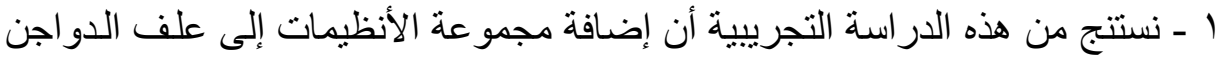

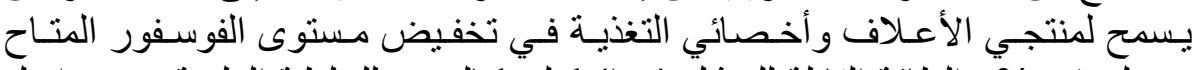

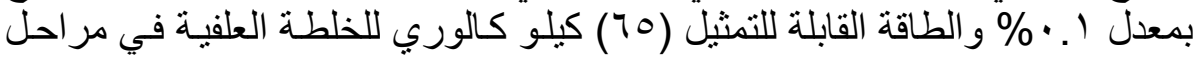

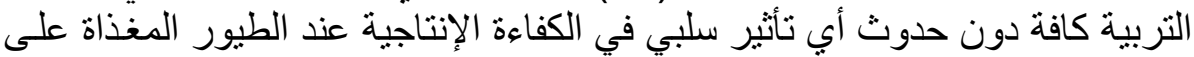

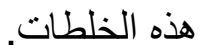

r - نستنج من هذه الدر اسة التجريبية أن إضافة مجمو عة الأنظيمات إلى علف الدواجن قد حسن الكفاءة الإنتاجية.

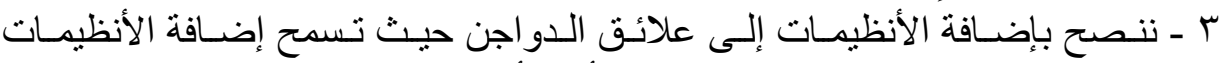

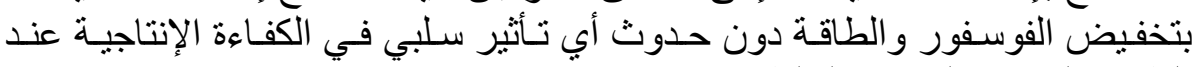
الطيور المغذاة على هذه الخلطات.

\section{REFERENCES

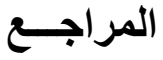

Barrier-Guillot, B. and Métayer, J.P. (2001): Valeur alimentaire de cinq matières premières chez le coq, le poulet de chair, le dindonneau et le canard. 4ièmes Journées de la Recherche Avicole, pp 131-134.

Bedford, M.R. (2000): Exogenous enzymes in monogastric nutrition-their current value and future benefits. Review article. Anim. Feed Sci. Technol., 86: 1-13.

Bedford, M.R. and Partridge, G.G. (2010): Enzymes in farm animal nutrition, 2nd edition, 3-315.

Cowieson, AJ. and Bedford, MR. (2009): The effect of phytase and carbohydrase on ileal amino acid digestibility in monogastricdiets: complimentary mode of action? World's Poultry Science Journal,65 :609-624 . . 
Cowieson, A.J. (2005): Factors that affect the nutritional value of maize for broilers. Anim. Feed Sci. Technol. 119: 293-305.

Cowieson, A.J. and Ravindran, V. (2008a): Effect of exogenous enzymes in maize-based diets varying in nutrient density for young broilers: Growth performance and digestibility of energy, minerals and amino acids. Br. Poult. Sci., 49: 37-44.

Cowieson, A.J. and Ravindran, V. (2008b): Sensitivity of broiler starters to three doses of an enzyme cocktail and amino acids. Br. Poult. Sci., 49: 37-44. in maize-based diets. Br. Poult. Sci., 49: 340-346.

Dalibard, P. and Geraert, P.A. (2004): Impact of a multi-enzyme preparation in corn-soybean poultry diets. Pages $1-5$ in Proc. Animal Feed Manufacturers Association Forum, Sun City, South Africa. De Wet Boshoff, Centurion, South Africa.

FAO (2009): Food Outlook, June edition, p. 27.

Francesch, M. and Geraert, P.A. (2009): Enzyme complex containing carbohydrases and phytase improves growth performance and bone mineralization of broilers fed reduced nutrient corn-soybean-based diets .Institute for Food and Agricultural Research and Technology,

Ghazi, S.; Rooke, J.A. and Galbraith, H. (2003): Improvement of the nutritive value of soybean meal by protease and alphagalactosidase treatment in broiler cockerels and broiler chicks. Br. Poult. Sci., 44: 410-418.

Janet C. Remus, (2008): Enzyme Combinations to Optimize Byproducts Use in Corn-Based Poultry Feed. Poult. Nut. Con., 35.

Jiang, Z.; Zhou, Y.; Lu, F.; Han, Z. and Wang, T. (2008): Effects of different levels of supplementary alpha- amylase on digestive enzyme activities and pancreatic amylase mRNA expression of young broilers. Asian-Austr. J. Anim. Sci., 21: 97-102.

Kocher, A.; Choct, M.; Ross, G.; Broz, J. and Chung, T.K. (2003):

Effects of enzyme combinations on apparent 
metabolizable energy of corn- soybean meal based diets in broilers. J. Appl. Poult. Res. 12: 275-283.

Liu, N.; Ru, Y.J.; Li, F.D. and Cowieson, A.J. (2008): Effect of phytate and phytase on the performance and immune function of broilers fed nutritionally marginal diets. Poult. Sci., 87: 1105-1111.

Maisonnier, S.; Grenier, P.; Dalibard, P.A. and Geraert, (2004): Benefit of NSP enzymes on corn soybean meal based diet in poultryAdisseo France S.A.S., 42 Avenue Aristide Briand, $92160 \quad$ Antony, E-mail: pierreandre.geraert@adisseo.com.

Reddy, V.R. and Quadratullah, S. (1997): Utilization of squilla meal (a novel animal protein source) by broilers. Br. Poult. Sci., 38: 263-269.

Ritz, C.W.; Hulet, R.M.; Self , B.B. and Denbow, D.M. (1995): Vieira, S.L., R.P. Ott, J.L.B. Coneglian and D.M. Freitas, Growth and intestinal morphology of male Turkeys as influenced by dietary supplementation of amylase and xylanase. Poult. Sci., 74: 1329-1334.

Rutherfurd, S.M.; Chung, T.K. and Moughan, P.J. (2007): The Effect of a Commercial Enzyme Preparation on Apparent Metabolizable Energy, the True Ileal Amino Acid Digestibility, and Endogenous Ileal Lysine Losses in Broiler Chickens. Poultry Science 86: 665-672.

Saleh, F.; Tahir, M.; Ohtsuka, A. and Hayashi, K. (2005): A mixture of pure cellulose, hemicellulase and pectinase improves broiler performance. Br. Poult. Sci., 46: 602-606.

Sauvant, D.; Perez, J.M. and Tran, G. (2002): Table de composition et de valeur nutritive des matières premières destinées aux animaux d'élevage (INRA edit.) Paris, pp 82-83 et pp 190-191.

Scheideler, S.E.; Beck, M.M.; Abudabos, A. and Wyatt, C. (2005): Multiple-enzyme (Avizyme) supplementation of corn-soy based layer diets. J. Applied Poult. Res., 14: 77-86.

Zanella, I.; Sakomura, N.K.; Silversides, F.G.; Fiqueirdo, A. and Pack, M. (1999): Effect of enzyme supplementation of 
Assiut Vet. Med. J. Vol. 58 No. 132 January 2012

broiler diets based on corn and soybeans. Poult. Sci. 78: 561-568. 